\title{
Depression, its correlates and quality of life of undergraduate medical students in the Kumaon region of Uttarakhand state, India
} Hariom Kumar Solanki ${ }^{1}$, Sadhana Awasthi ${ }^{2}$, Amandeep Kaur ${ }^{3}$, Gaihemlung Pamei ${ }^{4}$

${ }^{1}$ Assistant Professor, Department of Community Medicine, Govt. Institute of Medical Sciences, Greater Noida, GB Nagar, Uttar Pradesh, India; ${ }^{2}$ Professor \& Head, Department of Community Medicine, Government Medical College, Haldwani, Uttarakhand, India; ${ }^{3}$ Assistant Professor, Department of Community Medicine \& Family Medicine, All India Institute of Medical Sciences, Kalyani, West Bengal, India; ${ }^{4}$ Post Graduate Resident, Department of Community Medicine, Government Medical College, Haldwani, Uttarakhand, India

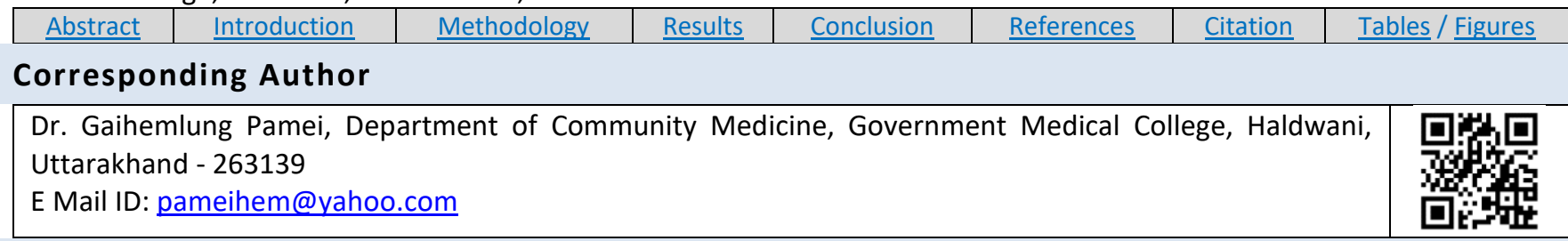

\section{Citation}

Solanki HK, Awasthi S, Kaur A, Pamei G. Depression, its correlates and quality of life of undergraduate medical students in the Kumaon region of Uttarakhand state, India. Indian J Comm Health. 2021;33(2):357-363. https://doi.org/10.47203/IJCH.2021.v33i02.023

Source of Funding: Nil Conflict of Interest: None declared

\section{Article Cycle}

Received: 01/03/2021; Revision: 13/05/2021; Accepted: 09/06/2021; Published: 30/06/2021

This work is licensed under a Creative Commons Attribution 4.0 International License.

\section{Abstract}

Background: Medical students are future health care providers and experience a lot of stress during their training years. They are more likely to suffer depressive disorders than the general population and have a poorer quality of life. Objectives: To determine the prevalence of depressive disorder, its correlates and quality of life of medical students studying at a medical college in North India. Methods and material: It was a cross sectional study which included all the students enrolled at the study medical college. Data was collected using pre-validated questionnaires namely - 20 item 'Center for Epidemiologic Studies Depression Scale (CES-D)', WHO Quality of life (QoL) - BREF questionnaire and 'Smartphone Addition Scale - Short version' (SAS-SV) questionnaire to assess for depression, quality of life and smartphone addiction respectively which was distributed in the classroom to be filled. Multivariate logistic regression was employed to ascertain association between depression and the other variables. Results: The study had an effective response rate of $79 \%$. Using a score of 16 or above as cut-off on CES-D scale145 study participants (36.7\%) were found to be depressed. Participants who negatively compared themselves with their peers/friends and also those who were addicted to smartphone were significantly more likely to be depressed [1.85(1.12-3.05) and 1.96 (1.29-2.97) respectively]. We report a statistically significant negative relationship between physical domain score [0.97(0.95-0.99)], psychological domain score [0.95(0.93-0.97)] and social relationship domain score [0.97(0.95-0.99)] on BREF Quality of life questionnaire and the presence of depression among the study participants. Conclusion: The prevalence of depression among medical students was high and those with depression have significantly poor quality of life.

\section{Keywords}

Mental health; Depression; Medical education; MBBS students; Smartphone addiction

\section{Introduction}

Medical students are future health care providers and multiple studies from India as well as outside India have reported that medical students experience tremendous amount of stress which is often related to academic factors, during their training years $(1,2)$. Literature suggests that medical students are more likely to suffer with depressive disorders than the general population and have a poorer quality of life. (3). Medical students may also not seek care for depressive symptoms because of self-perceived stigma related to the mental illness (4). In India medical students (MBBS students) undergo a four and half year of rigorous training and one-year mandatory rotatory internship before they receive license for independent practice (5). However, there is very little literature available regarding the prevalence of depressive 
disorders among medical students in India and especially in the Northern States of India.

\section{Aim \& Objective}

To determine the prevalence of depressive disorder, the correlates associated with depressive disorder and quality of life among medical students.

\section{Material \& Methods}

It was a cross sectional study conducted at a medical college in the Nainital District of the Kumaon region of the Uttarakhand State in India between June 2019 to November 2019. All undergraduate medical students enrolled at the study medical college at the time of study and available on the days of data collection were included in the study. The questionnaires were distributed by the investigators over a course of two weeks in the lecture halls after obtaining prior permission from the concerned teachers. Written informed consent was obtained from all the study participants after briefing them about the objectives of the study and assuring them confidentiality and anonymity of the data obtained during the study. The consent form was detached by the study participants themselves and handed over to the data collector separately. No information regarding personal identifiers like roll number or name was asked from the study participants during the study. Students who were absent on the day of the study were followed up twice and if absent on the third attempt were dropped out from the study. The study has approval from the institutional ethics committee vide letter no. 496/GMC/IEC/2019/Reg. No. 452/IEC/R-24-05-2019.

The socio-demographic profile of the students were obtained using a structured questionnaire and for data collection on the possibility of depressive disorder, 'Center for Epidemiologic Studies Depression Scale (CESD)' which is a 20 item, four (04) factor questionnaire and pre-validated for use in general population with the score ranging from 0-60 was used. A score of 16 or above was taken as suggestive of depressive disorder among the study participants (6). WHO Quality of life (QoL) - BREF questionnaire which consists of 26 questions related to four domains of quality of life - namely physical, psychological, social, and environmental domains; was used to assess the quality of life of the study participants. The raw scores obtained in each domain were converted to a scale of 0-100 using methodology as suggested (7). Smartphone addiction was measured using the prevalidated 'Smartphone Addition Scale - Short version' (SAS-SV) questionnaire. SAS-SV contains 10 questions whose responses can be made in a six (06) point Likert scale. The cut-off values used in the study for smartphone addiction were 31 and 33 for male and female students respectively (8). The study questionnaires were pretested before the final data collection.

Data entry was done in Microsoft Excel sheet and data analysis was done using Epi Info 7.2.2. Those participants who did not respond to all the items on the CES-D questionnaire or responded to less than 80 per cent items on SAS-SV questionnaire and on WHO Quality of life (QoL) - BREF questionnaire were excluded from the data analysis. Frequency distribution with percentage, mean with standard deviation (SD) and median with range/ inter-quartile range (IQR) has been reported where appropriate. For statistical testing 'Kruskal Wallis test' has been used for non-parametric data while Chi square test or Fischer exact test has been employed for qualitative and categorical variables. Two step multivariate logistic regression was employed to get adjusted estimates for the selected determinants. In the first step all the independent variables were entered in the logistic regression equation with presence or absence of depression as the dependent variable. All independent variables which had a ' $p$ ' value of 0.25 or less in the first step were identified and included as independent variables in the second iteration of logistic regression, while rest were excluded.

\section{Results}

A total of 414 out of maximum possible 500 students were included in the study (recruitment rate of 82.8 per cent). However, due to incomplete responses 29 participants were excluded from the final analysis so the results are being presented for 395 study participants (effective response rate of 79 per cent). From the five different batches starting from Batch 2014-15 to Batch 2018-19, the response rate varied from 60\% (Batch 2014-15) to $88 \%$ (Batch 2015-16). Almost three fifth of the study participants were females which reflects the higher enrolment of girl in the MBBS course at the study medical college appropriately (data not presented).

The Mean age of the study participants was 20.9 ( \pm 1.9$)$ years with a range of 17 years to 28 years. For both the girls and the boys the mean age and age range was similar in our study (data not presented). Very few study participants were married $(2.8 \%)$ or staying at home (5.3\%). About four fifth study participants had either one or both graduate parents. Only three percent study participants had both their parents with formal education of 10 years or less. Median family size of study participants was five family members with inter-quartile range of four to five members. However, the total range of family members extended from a low of three family members to a high of eleven members in the family (data not presented). Median family income as reported by participants in our study was INR 52,000 per month (IQR INR 40,000 - 80,000). (Table 1)

A total of 145 study participants (36.7\%) were having depression, using a score of 16 or above as cut-off on CESD scale. (Table 2). Though most of students were suffering from less severe form of depression (CES-D score between 16 and 30), a significant proportion (13.8\%) may be 
suffering from severe depression. The distribution of CESD score by gender has been presented in the (Table 2).

Participants who self-reported addiction to smartphone [1.96(1.29-2.97)] as well as participants found addicted to smartphone on SAS questionnaire [1.59(1.05-2.40)] were significantly more depressed compared to other participants who were not addicted to smartphone. Participants with chronic disease were thrice as likely to be depressed than others [3.28(1.51-7.10)]. Participants who felt that their siblings [1.93(1.12-3.31)] or friend [1.95(1.27-2.99)] were more accomplished than themselves were about twice as likely to be depressed compared to those who did not do so. Hospitalization of any family member for over 24 hours in last one year was also significantly associated with depression among the study participants [(1.7(1.12-2.58)]. More depressed study participants knew friends who they felt were depressed - though the finding was not statistically significant it was approaching statistical significance [1.51(0.99-2.29)]. Divorce or separation of parents, parental pressure for academic excellence, financial crisis in the family or romantic breakup of the study participants in last one year was associated with increased risk of depression but were not found statistically significant. Gender and marital status were not associated with depression in our study. (Table 3 )

Quality of life of the study participants was studied using BREF questionnaire under four domains as described above. All the four quality of life domain scores were adversely affected in study participants with depression both mean and median score were lower in depressed compared to non-depressed study participants in all the domains. The differences in median scores on BREF questionnaire were highly significant on statistical testing in all the domains. (Table 4)

To get adjusted estimates we performed logistic regression in two steps as mentioned in the methods section. The results thus obtained are presented in (Table 5). Those medical students who negatively compared themselves with their friends were significantly more likely to be depressed [1.85(1.12-3.05)]. In our study we found statistically significant negative relationship between physical domain score [0.97(0.95-0.99)], psychological domain score $[0.95(0.93-0.97)]$ and social relationship domain score [0.97(0.95-0.99)] on BREF Quality of life questionnaire and the presence of depression among study participants. Study participants who were having any chronic morbidity, felt that s/he was addicted to smartphone, experienced a financial crisis in their family or had their immediate family member hospitalized in the last one year from the date of data collection; were more likely to be depressed, however the findings were not statistically significant.

\section{Discussion}

We report a relatively high prevalence of depression among medical students at the study medical college in the Kumaon region of Uttarakhand state of India. Over a third of the students (36.7\%) were found to be depressed in our study. It is more than thirteen times $(2.7 \%)$ the prevalence of major depressive disorders prevalence in general population and over twenty times the prevalence of depression among 18-29 year age group people (1.6\%) in India as reported in the National Mental Health Survey of India 2015-16 (9). However, the study tools used in our study was different from the NMHS study tool which used the Mini International Neuro-psychiatric Interview (M.I.N.I 6.0). Another community-based study with large sample size from south India reported prevalence of depression to be $15.1 \%$ in general population after adjusting for age which is less than half the prevalence we report in our study.

From south Indian state of Kerala it was reported that the prevalence of depression among medical students varied from $36.2 \%$ to $42.8 \%$ over a follow up period of eighteen months which is similar to our study. Males were more likely to be depressed compared to females in their study, which is similar to findings in our study (10). In another study from eastern part of India more than half of the medical students were reported to be depressed (51.3\%). It was higher in 5th semester students compared to students of 2 nd semester unlike in our study where there were no significant differences in depression prevalence by batch of the students (data not presented). Unlike our study, females had higher score as compared to their male counterparts (11).

In the neighboring countries Nepal - touching Uttarakhand's borders - the prevalence of depression among medical students was reported to be $27.2 \%$ (21.3$33.1 \%),(12)$ while in the final year medical students in Pakistan it was over $57 \%$ (13). A systematic review from China identified prevalence of depression among medical students in China to be $32.7 \%$ - the range for individual studies varied from $13.1 \%$ to $76.2 \%$ (14). A systematic review and meta-analysis focusing on depression among medical students in Asian countries reported that the prevalence of depression among medical students in Asia was $11 \%$. The prevalence ranged from $3.2 \%$ to $70 \%$ in the studies included in the meta-analysis (15). At global level, a systematic review excluding studies with participants from North Americas found that depression prevalence among medical students varied from a low of $6 \%$ to as high as $66.5 \%$ (16). Though individual studies have reported varying degree of prevalence of depression among medical students and our study results are largely consistent with the findings reported in the literature.

In our study those students who felt that they were addicted to smartphone use were more likely to be depressed in the unadjusted analysis The finding is 
consistent with a systemic review and meta-analysis findings in which smartphone use and depression were found to be significantly associated [odds ratio 3.2(2.34.4)] (17). The relationship between using a smartphone excessively and depression is a likely to be bidirectional i.e., depressive mood may lead to increased probability of smartphone addiction, (18) as depressed individual may resort to frequently using the device to avoid unpleasant moods; (19) or it may also be possible that smartphone addiction may lead to depression which may be mediated through poor quality of sleep due to smartphone use (17). In our study those students who compared themselves unfavorably with siblings or friends and reported to have pressure of parents for academic reasons were more likely to be depressed on unadjusted analysis. The finding is similar to as reported from other studies (20). Medical students worried about their own health or having chronic illness are more likely to have mental health illnesses in future (21). We also report that medical students with chronic disease in themselves or having seen their family member hospitalized in past one year were found to be more likely to be depressed in unadjusted analysis. Students with family having financial crisis in last year were also more likely to be depressed in our study. Similar finding of low family income, family medical history and hospitalization - which may lead to financial insecurity and crisis - as a determinant of depression in medical students has been reported by a large study and a systematic review from China (14). Financial burden as a determinant of depression in medical students has been reported in other studies also (20).

Quality of life of the depressed study participants in our study was adversely affected in all the four domains environmental, physical, psychological and social relationship domains - and was found to be statistically significant on logistic regression analysis except for environmental domain. This finding is supported by other studies $(22,23)$. In medical students studying in Malaysia, quality of life in physical, psychological and environmental domains was significantly affected in depressed students (24). It has been reported that persistent depression may decrease satisfaction with social activities over time resulting in low score on social domain of WHO QOL scale, which also explain our findings (25).

As mentioned earlier, medical students experience a lot of stress during their training years; this may contribute in development of mental health disorders including depression among them. It has been reported that even a single session of appropriate intervention can reduce the depressive symptoms and improve quality of life among medical students (26). However in India so far no medical college or medical university - to best of authors knowledge - have implemented structured intervention or program to deal with the mental health problems of medical students. However, the Medical Council of India $(\mathrm{MCl})$, has notified changes in the curriculum and teaching-learning methods for medical students joining medical college from 2019-20 session (27). This new curriculum mandates among other things a one-month long foundation course at the beginning of the course which would include orientation of medical students to the whole course, sessions on time management, stress management, relaxing techniques and dedicated sessions for physical and creative activities so that students become familiar with each other - which may help in stress management. This may help to de-stress or at least in better management of stress by students themselves (28). However, the effectiveness of these measures will only become apparent after a lag of at least few years.

\section{Conclusion \& Recommendation}

In our study the prevalence of depression among medical students was high and those with depression have significantly poor quality of life. There is a need to address this problem on priority. Some of the useful measures could be establishment of student cell with counsellor, availability of a $24 \times 7$ mental health helpline number and group counselling sessions at regular intervals where time and stress management techniques could be taught to the students, in all medical colleges in India. Also, effective coping mechanisms to deal with stressful situations should be taught as part of the teaching curriculum. Sensitization of all faculty members (medical or nonmedical) to identify mental health issues among students and to provide basic support, counselling and referral if needed should also be done. There is need of more studies to document the prevalence of depression and effective interventions in medical college in India as are the studies to document the effectiveness of the new curriculum in decreasing mental health issues -especially depression among medical students in India

\section{Limitation of the study}

Our study is a population-based study at a single study site with a good response rate. Though studies have reported that the depression prevalence is higher when students are facing examinations, this should not be a significant factor in our study as the data was collected either after the examination were already finished or when the final examinations were about three months away from the time of data collection (29). However, we have not assessed for diagnosed case of depression, if any, at the same time we don't know whether the depression and quality of life among medical students who could not be included in the analysis was same as those included in the analysis. This may lead to under or over estimation of depression among medical students in our study depending upon whether they were more depressed or less depressed than those included in the study. It must also be remembered that this study is a cross-sectional study so any association/s should not be interpreted in directional way. 


\section{Relevance of the study}

The study concurs the surmounting evidence of depressio being the major problem among medical students.

\section{Authors Contribution}

All authors contributed equally.

\section{Acknowledgement}

The authors would like to thank the MBBS students who participated in the study.

\section{References}

1. Gupta S, Choudhury S, Das M, Mondol A, Pradhan R. Factors causing stress among students of a medical college in Kolkata, India. Educ Health (Abingdon). 2015;28(1):92-95. doi:10.4103/1357-6283.161924.

2. Rebello CR, Kallingappa PB, Hegde PG. Assessment of perceived stress and association with sleep quality and attributed stressors among 1st-year medical students: A cross-sectional study from Karwar, Karnataka, India. Ci Ji Yi Xue Za Zhi. 2018;30(4):221-226. doi:10.4103/tcmj.tcmj_85_17.

3. Pagnin D, de Queiroz V. Comparison of quality of life between medical students and young general populations. Educ Health (Abingdon). 2015;28(3):209-12. doi: 10.4103/1357-6283.178599. PMID: 26996647

4. Suwalska J, Suwalska A, Szczygieł M, Łojko D. Medical students and stigma of depression. Part 2. Self-stigma. Studenci medycyny a stygmatyzacja z powodu depresji. Część II. Autostygmatyzacja. Psychiatr Pol.

2017;51(3):503-513. doi:10.12740/PP/OnlineFirst/67373.

5. UG Curriculum | NMC [Internet]. Nmc.org.in. https://www.nmc.org.in/information-desk/for-colleges/ugcurriculum (Accessed on June 25, 2021)

6. Radloff, L. S. (1977). The CES-D Scale: A Self-Report Depression Scale for Research in the General Population. Applied Psychological Measurement, 1(3), 385-401. https://doi.org/10.1177/014662167700100306

7. WHOQOL - Measuring Quality of Lifel The World Health Organization. https://www.who.int/toolkits/whogol (Accessed on June 25, 2021)

8. Kwon, M., Kim, D. J., Cho, H., \& Yang, S. (2013). The smartphone addiction scale: development and validation of a short version for adolescents. PloS one, 8(12), e83558. https://doi.org/10.1371/journal.pone.0083558

9. National Mental Health Survey of India, 2015-2016 Prevalence, Patterns and Outcomes, Supported by Ministry of Health and Family Welfare, Government of India, and Implemented by National institute of Mental Health and Neurosciences (NIMHANS) Bengaluru: In Collaboration with Partner Institutions; 2015-2016. Available form http://indianmhs.nimhans.ac.in/Docs/Report2.pdf (Accessed on June 25, 2021)

10. Mohammed S, Tharayil H, Gopakumar S, George C. Pattern and Correlates of Depression among Medical Students: An 18.Month Follow-Up Study. Indian J Psychol Med. 2020;42(2):116-121. doi: 10.4103/IJPSYM.IJPSYM_28_19. PMID: 32346251; PMCID: PMC7173653.

11. Iqbal S, Gupta S, Venkatarao E. Stress, anxiety and depression among medical undergraduate students and their sociodemographic correlates. Indian J Med Res. 2015;141(3):354-7. doi: 10.4103/0971-5916.156571. PMID: 25963497; PMCID: PMC4442334.

12. Shrestha N, Shrestha N, Khanal S, Dahal S, Lama R, Simkhada P, Pradhan SN. Prevalence of Depression among Medical Students of a Tertiary Care Teaching Hospital. JNMA J Nepal Med Assoc. 2019;57(220):403-407.

13. Kumar B, Shah MAA, Kumari R, Kumar A, Kumar J, Tahir A. Depression, Anxiety, and Stress Among Final-year Medical
Students. Cureus. 2019;11(3):e4257. doi: 10.7759/cureus.4257. PMID: 31139516; PMCID: PMC6519980.

14. Mao Y, Zhang N, Liu J, Zhu B, He R, Wang X. A systematic review of depression and anxiety in medical students in China. BMC Med Educ. 2019;19(1):327. doi: 10.1186/s12909-019-1744-2. PMID: 31477124; PMCID: PMC6721355.

15. Cuttilan AN, Sayampanathan AA, Ho RC. Mental health issues amongst medical students in Asia: a systematic review [20002015]. Ann Transl Med. 2016;4(4):72. doi: 10.3978/j.issn.23055839.2016.02.07. PMID: 27004219; PMCID: PMC4779785.

16. Hope V, Henderson M. Medical student depression, anxiety and distress outside North America: a systematic review. Med Educ. 2014;48(10):963-979. doi:10.1111/medu.12512.

17. Rotenstein LS, Ramos MA, Torre M, Segal JB, Peluso MJ, Guille C et al. Prevalence of Depression, Depressive Symptoms, and Suicidal Ideation Among Medical Students: A Systematic Review and MetaAnalysis. JAMA. 2016;316(21):2214-2236. doi:10.1001/jama.2016.17324.

18. Sohn, S.Y., Rees, P., Wildridge, B. et al. Prevalence of problematic smartphone usage and associated mental health outcomes amongst children and young people: a systematic review, metaanalysis and GRADE of the evidence. BMC Psychiatry 19, 356 (2019). https://doi.org/10.1186/s12888-019-2350-x

19. Alavi SS, Ghanizadeh M, Farahani M, Jannatifard F, Esmaili Alamuti S, Mohammadi MR. Addictive Use of Smartphones and Mental Disorders in University Students. Iran J Psychiatry. 2020;15(2):96104. PMID: 32426005; PMCID: PMC7215249.

20. De-Sola Gutiérrez J, Rodríguez de Fonseca F, Rubio G. Cell-Phone Addiction: A Review. Front Psychiatry. 2016;7:175. doi: 10.3389/fpsyt.2016.00175. PMID: 27822187; PMCID: PMC5076301.

21. Pacheco JP, Giacomin HT, Tam WW, Ribeiro TB, Arab C, Bezerra IM, Pinasco GC. Mental health problems among medical students in Brazil: a systematic review and meta-analysis. Braz J Psychiatry. 2017;39(4):369-378. doi: 10.1590/1516-4446-2017-2223. Epub 2017 Aug 31. PMID: 28876408 ; PMCID: PMC7111407.

22. Borst JM, Frings-Dresen MH, Sluiter JK. Prevalence and incidence of mental health problems among Dutch medical students and the study-related and personal risk factors: a longitudinal study. Int J Adolesc Med Health. 2016;28(4):349-355.doi:10.1515/ijamh-20150021.

23. Moutinho ILD, Lucchetti ALG, Ezequiel ODS, Lucchetti G. Mental health and quality of life of Brazilian medical students: Incidence, prevalence, and associated factors within two years of follow-up. Psychiatry Res. 2019;274:306312.doi:10.1016/j.psychres.2019.02.041.

24. Gan GG, Yuen Ling H. Anxiety, depression and quality of life of medical students in Malaysia. Med J Malaysia. 2019 Feb;74(1):5761. PMID: 30846664.

25. Silva V, Costa P, Pereira I, Faria R, Salgueira AP, Costa MJ, et al. Depression in medical students: insights from a longitudinal study. BMC Med Educ. 2017;17(1):184. Published 2017 Oct 10. doi:10.1186/s12909-017-1006-0.

26. Bermudez MB, Costanzi M, Macedo MJA, et al. Improved quality of life and reduced depressive symptoms in medical students after a single-session intervention. Braz J Psychiatry. 2020;42(2):145-152. doi:10.1590/1516-4446-2019-0526.

27. NMC. Competency Based Assessment Module for Undergraduate Medical Education. Nmc.org.in. Accessed on June 25, 2021. https://www.nmc.org.in/information-desk/for-colleges/ugcurriculum .

28. (No Title) Accessed Jun 21, 2020. https://www.nmc.org.in/wpcontent/uploads/2020/08/FOUNDATION-COURSE-MBBS17.07.2019.pdf

29. Thiemann P, Brimicombe J, Benson J, Quince T. When investigating depression and anxiety in undergraduate medical students timing of assessment is an important factor - a multicentre cross-sectional study. BMC Med Educ. 2020;20(1):125. doi:10.1186/s12909-02002029-0. 


\section{Tables}

\begin{tabular}{|c|c|c|c|}
\hline Variable & Description & Frequency/Mean/Median & $\%$ / SD/ IQR \\
\hline \multirow[t]{2}{*}{ Gender } & Male & 154 & $39.0 \%$ \\
\hline & Female & 241 & $61.0 \%$ \\
\hline \multirow[t]{2}{*}{ Marital status } & Married & 11 & $02.8 \%$ \\
\hline & Unmarried & 384 & $97.2 \%$ \\
\hline \multirow[t]{2}{*}{ Residence } & Hostel & 374 & $94.7 \%$ \\
\hline & Home & 21 & $05.3 \%$ \\
\hline \multirow[t]{5}{*}{ Highest family Education } & Graduation or above & 312 & $79.0 \%$ \\
\hline & $\geq 10$ but no graduation & 48 & $12.2 \%$ \\
\hline & $<10$ & 12 & $03.0 \%$ \\
\hline & Unknown for both parents & 19 & $04.8 \%$ \\
\hline & $\begin{array}{l}\text { Unknown for one parent with other } \\
\text { parent not a graduate }\end{array}$ & 4 & $01.0 \%$ \\
\hline Age (years) & Mean (SD) & 20.9 & 1.9 \\
\hline Family income in INR ( $n=314)$ & Median (IQR) & 52000 & $40000-80000$ \\
\hline Family size $(n=385)$ & Median (IQR) & 5 & $4-5$ \\
\hline
\end{tabular}

TABLE 2 DISTRIBUTION OF CES-D SCORE AMONG THE STUDY PARTICIPANTS ( $\mathrm{N}=395$ )

\begin{tabular}{|c|c|c|c|c|c|}
\hline CES-D Score & \multicolumn{2}{|c|}{ Male $n(\%)$} & \multicolumn{2}{|c|}{ Female $\mathbf{n}(\%)$} & Total n (\%) \\
\hline$<5$ & \multicolumn{2}{|c|}{11 (27.5\%) } & & 29 (72.5\%) & $40(100 \%)$ \\
\hline $6-10$ & \multicolumn{2}{|c|}{$41(37.6 \%)$} & & $68(62.4 \%)$ & $109(100 \%)$ \\
\hline $11-15$ & \multicolumn{2}{|c|}{$42(41.6 \%)$} & & $59(58.4 \%)$ & $101(100 \%)$ \\
\hline $16-20$ & \multicolumn{2}{|c|}{$25(37.3 \%)$} & & $42(62.7 \%)$ & 67 (100\%) \\
\hline $21-25$ & \multicolumn{2}{|c|}{$12(31.6 \%)$} & & $26(68.4 \%)$ & $38(100 \%)$ \\
\hline $26-30$ & \multicolumn{2}{|c|}{$12(60.0 \%)$} & & $8(40.0 \%)$ & $20(100 \%)$ \\
\hline $31-35$ & \multicolumn{2}{|c|}{$4(40.0 \%)$} & & $6(60.0 \%)$ & $10(100 \%)$ \\
\hline $36-40$ & \multicolumn{2}{|c|}{$5(71.4 \%)$} & & $2(28.6 \%)$ & $7(100 \%)$ \\
\hline$>40$ & \multicolumn{2}{|c|}{$2(66.7 \%)$} & & $1(33.3 . \%)$ & $3(100 \%)$ \\
\hline Total participants with CES-D score $\geq 16$ & \multicolumn{2}{|c|}{$60(15.2 \%)$} & \multicolumn{2}{|r|}{$85(21.5 \%)$} & $395(100 \%)$ \\
\hline TABLE 3 ASSOCIATION OF SELECTED & LES WITH D & SSIO & AMO & G STUDY P & PANTS $(\mathrm{N}=395$ \\
\hline \multirow[t]{2}{*}{ Variable } & \multirow[t]{2}{*}{ Description } & \multicolumn{2}{|c|}{ Depression } & \multirow[t]{2}{*}{ OR (Cl) } & \multirow[t]{2}{*}{$P$ value } \\
\hline & & Yes & No & & \\
\hline \multirow[t]{2}{*}{ Gender } & Female & 85 & 156 & \multirow[t]{2}{*}{$0.85(0.56-1.30)$} & \multirow[t]{2}{*}{0.520} \\
\hline & Male & 60 & 94 & & \\
\hline Addicted to smartphone & Yes & 76 & 90 & $1.96(1.29-2.97)$ & 0.002 \\
\hline & No & 69 & 160 & & \\
\hline Break up & Yes & 28 & 33 & $1.57(0.91-2.73)$ & 0.105 \\
\hline & No & 117 & 217 & & \\
\hline Compare with sibling & Yes & 32 & 32 & $1.93(1.12-3.31)$ & 0.023 \\
\hline & No & 113 & 218 & & \\
\hline Chronic disease & Yes & 19 & 11 & $3.28(1.51-7.10)$ & 0.003 \\
\hline & No & 126 & 229 & & \\
\hline Compare with friend & Yes & 64 & 72 & $1.95(1.27-2.99)$ & 0.003 \\
\hline & No & 81 & 178 & & \\
\hline Death in Family & Yes & 24 & 39 & $1.07(0.62-1.87)$ & 0.920 \\
\hline & No & 121 & 211 & & \\
\hline Depressed Friend & Yes & 66 & 89 & $1.51(0.99-2.29)$ & 0.066 \\
\hline & No & 79 & 161 & & \\
\hline Divorce/ separation of parents & Yes & 4 & 2 & $3.52(0.64-19.45)$ & 0.270 \\
\hline & No & 141 & 248 & & \\
\hline
\end{tabular}




\begin{tabular}{|c|c|c|c|c|c|}
\hline \multicolumn{4}{|c|}{ INDIAN JOURNAL OF COMMUNITY HEALTH / VOL 33 / ISSUE NO 02 / APR- JUN 2021} & \multicolumn{2}{|c|}{ [Depression, its correlates...] | Solanki HK et al } \\
\hline \multirow[t]{2}{*}{ Failure in a major exam (last 1 year) } & Yes & 13 & 27 & \multirow[t]{2}{*}{$0.81(0.41-1.63)$} & \multirow{2}{*}{0.680} \\
\hline & No & 132 & 223 & & \\
\hline \multirow[t]{2}{*}{ Financial crisis (last 1year) } & Yes & 15 & 14 & \multirow[t]{2}{*}{$1.95(0.91-4.2)$} & \multirow[t]{2}{*}{0.120} \\
\hline & No & 130 & 236 & & \\
\hline \multirow[t]{2}{*}{ Hospitalization of any family member } & Yes & 67 & 84 & \multirow[t]{2}{*}{$1.7(1.12-2.58)$} & \multirow[t]{2}{*}{0.017} \\
\hline & No & 78 & 166 & & \\
\hline \multirow[t]{2}{*}{ Residence (usual) } & Home & 9 & 12 & \multirow[t]{2}{*}{$1.31(0.54-3.19)$} & \multirow[t]{2}{*}{0.710} \\
\hline & Hostel & 136 & 238 & & \\
\hline \multirow[t]{2}{*}{ Parental pressure for academic reason } & Yes & 16 & 16 & \multirow[t]{2}{*}{$1.81(0.88-3.75)$} & \multirow[t]{2}{*}{0.150} \\
\hline & No & 129 & 234 & & \\
\hline \multirow[t]{2}{*}{ Addicted to smartphone (SAS-SV) } & Yes & 74 & 99 & \multirow[t]{2}{*}{$1.59(1.05-2.40)$} & \multirow[t]{2}{*}{0.035} \\
\hline & No & 71 & 151 & & \\
\hline
\end{tabular}

\begin{tabular}{|c|c|c|c|c|c|c|c|}
\hline \multirow[t]{2}{*}{ Quality of life domain } & \multirow[t]{2}{*}{ Participants } & \multicolumn{5}{|c|}{ BREF Score (0-100) } & \multirow[t]{2}{*}{ 'P' value* } \\
\hline & & Mean & SD & Median & IQR & Range & \\
\hline \multirow[t]{3}{*}{ Physical domain } & All $(n=395)$ & 65.25 & 14.87 & 69 & $56-75$ & $13-100$ & \\
\hline & No Depression & 68.65 & 13.05 & 69 & $63-81$ & $19-100$ & \multirow[t]{2}{*}{$<0.001$} \\
\hline & Depressed & 59.40 & 16.00 & 63 & $50-69$ & $13-100$ & \\
\hline \multirow[t]{3}{*}{ Psychological domain } & All $(n=395)$ & 61.83 & 15.15 & 63 & $50-69$ & $13-94$ & \\
\hline & No Depression & 66.82 & 12.42 & 69 & $56-75$ & $31-94$ & \multirow[t]{2}{*}{$<0.001$} \\
\hline & Depressed & 53.22 & 15.60 & 56 & $44-63$ & $13-94$ & \\
\hline \multirow[t]{3}{*}{ Social Relationship domain } & All $(n=395)$ & 59.09 & 13.35 & 69 & $50-75$ & $0-69$ & \\
\hline & No Depression & 62.01 & 10.76 & 69 & $56-69$ & $19-69$ & \multirow[t]{2}{*}{$<0.001$} \\
\hline & Depressed & 54.06 & 15.73 & 56 & $50-69$ & $0-69$ & \\
\hline \multirow[t]{3}{*}{ Environmental domain } & All $(n=395)$ & 63.77 & 13.47 & 63 & $56-75$ & $19-100$ & \\
\hline & No Depression & 66.46 & 12.42 & 69 & $63-75$ & $19-100$ & \multirow[t]{2}{*}{$<0.001$} \\
\hline & Depressed & 59.15 & 13.98 & 63 & 50-69 & $25-94$ & \\
\hline
\end{tabular}

\begin{tabular}{|c|c|c|c|c|}
\hline Variable & aOR & $\mathrm{Cl}$ & Coeff. & P value \\
\hline Chronic disease (Y/N) & 1.82 & $0.71-4.70$ & 0.599 & 0.216 \\
\hline Comparison with friends $(\mathrm{Y} / \mathrm{N})$ & 1.85 & $1.12-3.05$ & 0.615 & 0.016 \\
\hline Family education ( $<10 / 10-12 /$ Graduation) & 1.02 & $0.99-1.04$ & 0.017 & 0.243 \\
\hline Financial crisis $(\mathrm{Y} / \mathrm{N})$ & 2.16 & $0.84-2.31$ & 0.771 & 0.110 \\
\hline Hospitalization of family member $(\mathrm{Y} / \mathrm{N})$ & 1.41 & $0.85-2.31$ & 0.341 & 0.179 \\
\hline Smartphone addiction on SAS-SV (Y/N) & 0.67 & $0.39-1.17$ & -0.396 & 0.159 \\
\hline Parental pressure on academics $(\mathrm{Y} / \mathrm{N})$ & 0.48 & $0.19-1.22$ & -0.733 & 0.124 \\
\hline Physical domain score (BREF) & 0.97 & $0.95-0.99$ & -0.028 & 0.008 \\
\hline Psychological domain score (BREF) & 0.95 & $0.93-0.97$ & -0.050 & $<0.001$ \\
\hline Self-reported smartphone addiction $(\mathrm{Y} / \mathrm{N})$ & 1.60 & $0.93-2.76$ & 0.471 & 0.089 \\
\hline Social Relationship domain score (BREF) & 0.97 & $0.95-0.99$ & -0.032 & 0.001 \\
\hline Constant & & & 5.877 & \\
\hline
\end{tabular}

